\title{
QUALIDADE DE ÁGUAS SUBTERRÂNEAS CAPTADAS EM FONTES EM FUNÇÃO DA PRESENÇA DE PROTEÇÃO FÍSICA E DE SUA POSIÇÃO NA PAISAGEM ${ }^{1}$
}

\author{
DANILO DOS S. RHEINHEIMER ${ }^{2}$, CELSO S. GONÇALVES ${ }^{3}$, EDSON C. BORTOLUZZI ${ }^{4}$, \\ JOÃO B. R. PELLEGRINI ${ }^{5}$, JOSÉ L. S. DA SILVA ${ }^{6}$, CLÁUDIA PETRY ${ }^{7}$
}

RESUMO: No meio rural, a água de consumo humano é frequentemente captada por meio de sistemas precários. O objetivo do trabalho foi o de monitorar parâmetros físicos, químicos e microbiológicos da qualidade de água subterrânea captada em fontes para uso doméstico, relacionando suas posições na paisagem e à presença de proteção física. Trinta e cinco fontes de água subterrânea, localizadas na pequena bacia hidrográfica-PBH do Arroio Lino, área rural do Município de Agudo - RS, foram amostradas e classificadas quanto à proteção física e à posição na paisagem. Monitoraram-se, de janeiro a agosto de 2002, os seguintes parâmetros da água: pH, cor, carbono orgânico solúvel total (COST), N$\mathrm{NO}_{3}, \mathrm{~N}-\mathrm{NH}_{3}$ e fósforo total (PT), Escherichia coli e coliformes totais. Em geral, os parâmetros variaram com a época de coleta, ficando ora acima, ora abaixo dos Valores Máximos Permissíveis previstos pelo Ministério da Saúde do Brasil. A posição das fontes nas cotas mais altas da paisagem da PBH mostrouse determinante unicamente para a cor e o PT. A proteção rudimentar mostrou-se eficaz para o PT nas fontes posicionadas em cotas altas, no entanto apresentou respostas discrepantes na parte baixa da paisagem, considerando-se os parâmetros COST e N-NO . A fonte drenada coletiva, sistema recomendado pela assistência técnica oficial, mostrou-se a mais eficaz em evitar a contaminação por Escherichia coli, restringindo também coliformes totais, fósforo total e $\mathrm{N}^{-\mathrm{NO}_{3}}$ em relação à fonte individual. A posição das fontes na paisagem e a presença de proteção física rudimentar podem ser utilizadas como critério parcial ao uso de fontes para captação de água.

PALAVRAS-CHAVE: abastecimento rural, manejo do solo, saúde pública, contaminação da água.

\section{QUALITY OF GROUND WATER TAKEN FROM SOURCES IN FUNCTION OF THE PRESENCE OF PHYSICAL PROTECTION AND THE POSITION IN THE LANDSCAPE}

ABSTRACT: In rural areas, water for human consumption is often captured by insecure systems. The objective of this work was monitoring some parameters of the quality of groundwater taken from sources, pointing out their position in the landscape and the presence of physical protection. For this , 36 sources in the watershed of Arroio Lino, a rural area of Agudo, RS, Brazil, were sampled and classified according their physical protection and position in the landscape. A monitoring program, from January to August 2002, was carried out to analyze the following parameters: $\mathrm{pH}$, color, total soluble organic carbon - TSOC, N-NO, $\mathrm{N}_{3} \mathrm{NH}_{3}$ and total phosphorus, E. coli and total coliforms. The parameters values changed with the time of collection and were often above the Maximum Allowable values provided by the Brazilian Ministry of Health. A rudimentary protection was efficient to the PT of the sources located in high levels; however it has present discrepant results for the low part of the landscape, considering the parameters TSOC e N$\mathrm{NO}_{3}$. The collective drained source, system recommended by the official technical assistance, was the most efficient to avoid contamination by Escherichia coli, restricting also the levels of total coliforms, total phosphorus and $\mathrm{N}-\mathrm{NO}_{3}$ as compared to the individual sources. The sources position in the landscape and the presence of a rudimentary physical protection can be employed as a partial criterion to accept that a water source be used for collecting water.

KEYWORDS: rural supplies, soil management, health public, water contamination.

\footnotetext{
${ }^{1}$ Trabalho apoiado financeiramente pelo programa RS-RURAL, CNPq, FAPERGS.

${ }^{2}$ Eng $^{\circ}$ Agrônomo, Doutor, Pesquisador CNPq PQ 1D, CCR-UFSM, Santa Maria - RS, danilo@ ccr.ufsm.br.

${ }^{3}$ Eng ${ }^{0}$ Agrônomo, Doutor, Professor, IFET, São Vicente do Sul - RS, celsocefet @ gmail.com.

${ }^{4}$ Eng ${ }^{0}$ Agrônomo, Doutor, Pesquisador CNPq PQ 2, FAMV-UPF, Passo Fundo - RS, edson.bortoluzzi@pq.cnpq.br.

${ }^{5}$ Eng ${ }^{\text {o }}$ Agrônomo, Doutor, Professor, IFET-UNED, Júlio de Castilhos - RS, jbpellegrini@ yahoo.com.br.

${ }^{6}$ Geólogo, Doutor, Pesquisador CNPq PQ 2, UFSM, Santa Maria - RS, silverioufsm@ gmail.com.

${ }^{7}$ Eng ${ }^{\mathrm{o}}$ Agrônomo, Doutor, Professor, FAMV-UPF, Passo Fundo - RS, petry@upf.br.

Recebido pelo Conselho Editorial em: 3-4-2009
}

Aprovado pelo Conselho Editorial em: 3-9-2010 


\section{INTRODUÇÃO}

Águas subterrâneas são consideradas imprescindíveis ao consumo humano, principalmente para $19 \%$ da população brasileira que a utilizam por meio de instalações precárias de captação. Em pequenas bacias hidrográficas de cabeceiras $(\mathrm{PBH})$, a água subterrânea verte por meio de nascentes incrustadas em morros cobertos com ampla cobertura florestal, apresentando normalmente padrão de potabilidade (BRASIL, 2004). Contudo, a ação antrópica em áreas rurais (DONADIO et al., 2005; ANDRADE et al., 2007), por meio de ações como: cultivo em áreas inapropriadas ou de preservação (RHEINHEIMER et al., 2003; MINELLA et al., 2007), uso de agrotóxicos (BORTOLUZZI et al., 2006 e 2007; GRÜTZMACHER et al., 2008; FERNANDES NETO \& SARCINELLI, 2009), substituição da mata nativa por espécie exótica (BUENO et al., 2005), adubação fosfatada (ANDRADE et al., 2007) e ausência de tratamento de dejetos (SANTOS et al., 2007) alteram os parâmetros de potabilidade das águas, conferindo à atividade agrícola um grande potencial poluidor. Somente no Rio Grande do Sul, estima-se que cerca de 90 mil pequenas propriedades podem enquadrar-se nessa configuração de exploração.

Inúmeros estudos têm apontado para a necessidade de diminuir a pressão antrópica sobre as áreas rurais como modo de preservar a qualidade das águas (RHEINHEIMER et al., 2003; MERTEN \& MINELLA, 2006; ANDRADE et al., 2007; MINELLA et al., 2007). Por outro lado, medidas emergenciais, como a construção de fontes nas partes mais elevadas do relevo e com proteção em alvenaria, podem ser eficazes na manutenção da potabilidade da água (RHEINHEIMER et al., 2003). Entre as alternativas baratas e eficazes, destaca-se a implantação de fontes drenadas que captam a água subterrânea do lençol freático, filtram-na por meio de areia e brita graduada, armazenando-a em reservatórios.

Apesar dessas iniciativas, a eficiência de sistemas de proteção de fontes de água é controversa (AMARAL et al., 2003), necessitando de uma avaliação. O monitoramento da qualidade da água pode ser uma importante ferramenta de avaliação, indicando se proteções em fontes são eficazes se práticas agrícolas têm relação com a qualidade da água (PIZZELLA \& SOUZA, 2007; BUENO et al., 2005). Nesse sentido, o presente trabalho teve como objetivos: a) determinar espacial e temporalmente parâmetros físicos, químicos e microbiológicos da qualidade de água subterrânea captada em fontes, e b) relacionar esses parâmetros quanto à posição das fontes na paisagem e à presença de proteção física. Visa-se com isso a contextualizar as práticas de proteção de fontes frente ao uso do solo em uma pequena bacia hidrográfica e à necessidade de planejamento de solos e ambiental em microbacias hidrográficas.

\section{MATERIAL E MÉTODOS}

O estudo foi realizado na pequena bacia hidrográfica de cabeceira do Arroio Lino, localizada no Distrito de Nova Boêmia, município de Agudo - RS. Com 480 ha de área, a PBH apresenta a litologia composta por rochas vulcânicas da Formação Serra Geral e por arenitos em interderrames da Formação Botucatu. Os solos são do tipo Argissolos, Planossolos, Cambissolos, Neossolos e Chernossolos. A vegetação natural é a floresta estacional decídua, porém grandes áreas estão florestadas por matas secundárias, indicando que outrora a área fora cultivada. Existem 46 unidades de produção familiar que cultivam fumo em sistema de integração com a indústria. As lavouras localizadas em áreas suscetíveis à erosão são preparadas com lavrações e gradagens, onde o uso de agrotóxicos e fertilizantes é uma constante.

Localizou-se na área um total de 36 fontes de água destinadas ao abastecimento humano por meio de fotos aéreas e de carta do exército. As fontes foram georreferenciadas com uso de receptor GPS de navegação e classificadas quanto a sua localização na paisagem e à presença de proteção física, instalações, benfeitorias e uso do solo em suas adjacências (Figura 1). Cada fonte consiste em um poço escavado para acesso da água subterrânea. Nelas, amostras de água foram coletadas com frequência mensal, entre os meses de janeiro e agosto de 2002, e encaminhadas ao Laboratório de Análises de Águas Rurais da Universidade Federal de Santa Maria. 


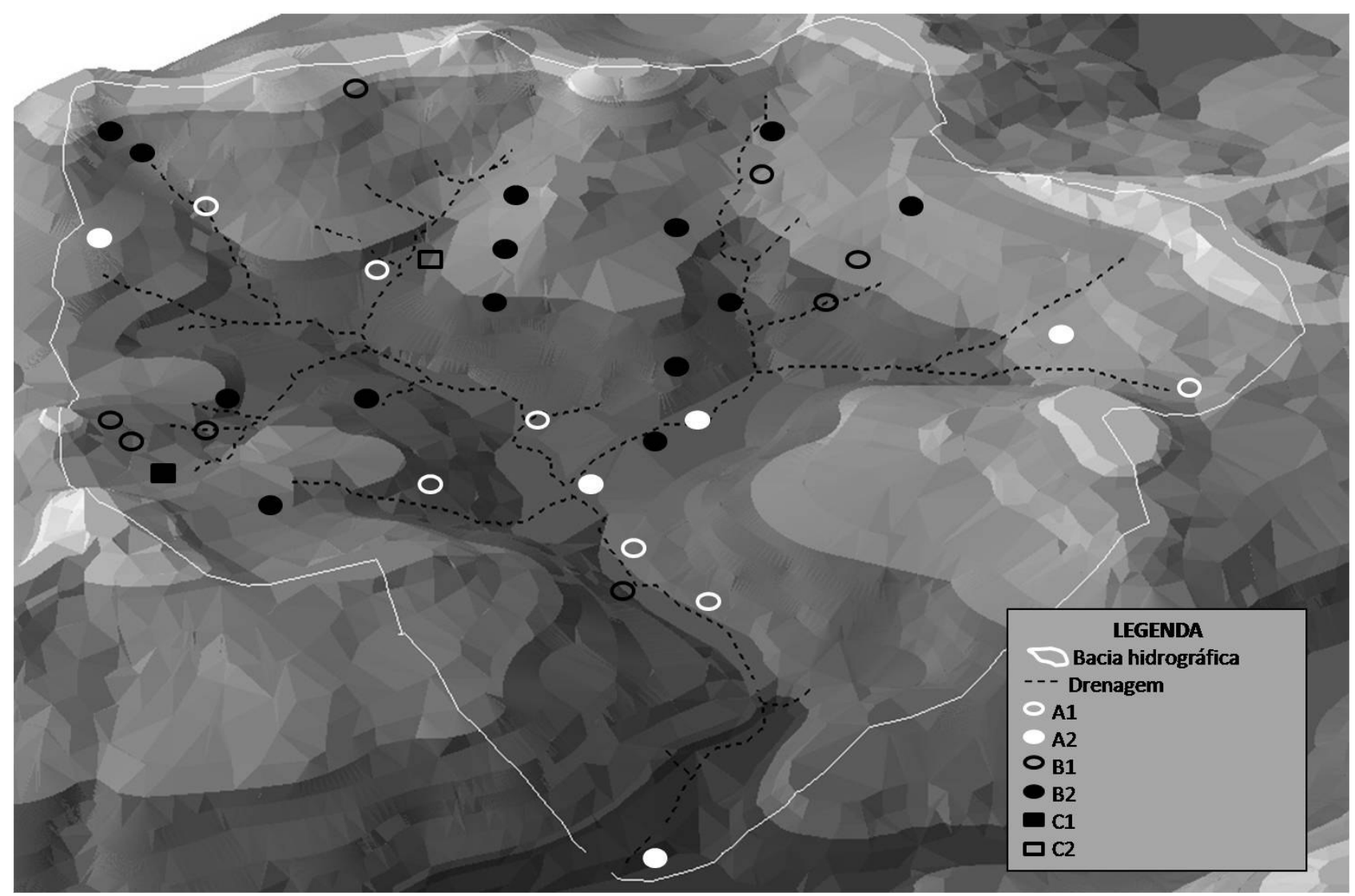

FIGURA 1. Mapa temático da Microbacia Hidrográfica do Arroio Lino, indicando geograficamente os pontos de coleta das amostras. $\mathrm{A}=$ fontes de baixada; $\mathrm{B}=$ fontes de encosta; 1 e $2=$ ausência ou presença de proteção física; $\mathrm{C} 1$ e C2 = fontes drenadas individual e coletiva. Thematic map of the Watershed, indicating geographically the points of sample collection. $A=$ downhill sources, $B=$ slope sources, 1 and 2 the absence or presence of physical protection; $\mathrm{C} 1$ and $\mathrm{C} 2$ drained sources individually and collectively.

Para a coleta das amostras destinadas à análise microbiológica, foram usados frascos de vidro do tipo "snap-cap", com capacidade para $100 \mathrm{~mL}$, previamente lavados com $\mathrm{HCl} 0,1 \mathrm{~mol} \mathrm{~L}^{-1} \mathrm{e}$ esterilizados em autoclave, sob uma atmosfera e $121{ }^{\circ} \mathrm{C}$. Para as amostras destinadas ás análises físicas e químicas, utilizaram-se frascos de plástico com capacidade para $300 \mathrm{~mL}$, igualmente limpos com a mesma solução. O procedimento de coleta constou da abertura e submersão dos frascos na água das fontes entre 15 e $20 \mathrm{~cm}$ de profundidade, de modo a completá-los até atingirem 3/4 de sua capacidade, posteriormente tampados e acondicionados em caixa térmica com gelo.

No laboratório, as determinações microbiológicas consistiram na estimativa do número mais provável (NMP) de coliformes totais e de Escherichia coli, expresso em NMP $100 \mathrm{~mL}^{-1}$, seguindo o método cromogênico-fluorogênico (APHA, 1992). Nas amostras de água, determinaram-se: a cor; o $\mathrm{pH}$; a condutividade elétrica - CE; a concentração $\mathrm{mg} \mathrm{L}^{-1}$ de sólidos totais dissolvidos - STD, de nitrato - $\mathrm{N}-\mathrm{NO}_{3}$; de N-amoniacal - N-NH ; carbono orgânico solúvel total - COST, e fósforo total PT (APHA, 1992).

As fontes de água subterrâneas da PBH foram agrupadas em seis subgrupos: A1, A2, B1, B2, C1 e C2 (Tabela 1), conforme a posição na paisagem e a presença de proteção. As fontes do grupo A são locadas nas cotas mais baixas do terreno (paisagem de baixada), entre 160 e $350 \mathrm{~m}$ de altitude, sendo passíveis de receberem água do deflúvio superficial; as fontes do subgrupo A1 não possuem proteção física, enquanto as do A2 as possuem. As fontes do grupo B estão nas cotas 
superiores do terreno, entre 310 e $400 \mathrm{~m}$ de altitude (paisagem de encosta), em áreas menos propícias à atividade humana. As fontes dos subgrupos B1 não possuem proteção física, enquanto as do subgrupo B2 as possuem. A proteção física presente nas fontes A1 e B1 consiste em estruturas de alvenaria que tentam isolar as fontes à entrada de água e materiais externos. Constituem-se também em tubos de concreto circundando a fonte, reservatórios em alvenaria e caixas de água de fibrocimento, ou mesmo de amianto, onde a água imediatamente após seu afloramento é direcionada para o reservatório.

TABELA 1. Características de 36 fontes de água utilizadas para abastecimento humano na pequena bacia hidrográfica do Arroio Lino - Agudo - RS Characteristics of 36 groundwater sources used for human consumption in Arroio Lino watershed, Agudo, RS.

\begin{tabular}{|c|c|c|c|c|c|c|c|c|}
\hline \multirow[t]{2}{*}{ Grupo } & \multirow[t]{2}{*}{ Localização } & \multirow[t]{2}{*}{$\begin{array}{l}\text { Número } \\
\text { Total de } \\
\text { Fontes }\end{array}$} & \multirow[t]{2}{*}{$\begin{array}{l}\text { Proteçãa } \\
\text { Física }\end{array}$} & \multirow[t]{2}{*}{ Uso do Solo } & \multicolumn{4}{|c|}{$\begin{array}{c}\text { Benfeitorias Localizadas a }<50 \mathrm{~m} \text { de } \\
\text { Distância das Fontes } \\
\text { (número/total de fontes) }\end{array}$} \\
\hline & & & & & Pocilgas & Casas & Lavouras & Estradas \\
\hline A1 & Baixada & 7 & Ausente & $\begin{array}{c}\text { Campo, } \\
\text { capoeira, mata }\end{array}$ & $2 / 7$ & $4 / 7$ & $4 / 7$ & $5 / 7$ \\
\hline A2 & Baixada & 5 & Presente & $\begin{array}{c}\text { Campo, } \\
\text { capoeira, mato }\end{array}$ & $2 / 5$ & $2 / 5$ & $2 / 5$ & $4 / 5$ \\
\hline B1 & Encosta & 8 & Ausente & $\begin{array}{c}\text { Mato, } \\
\text { capoeira }\end{array}$ & $0 / 7$ & $0 / 7$ & $3 / 7$ & $2 / 7$ \\
\hline B2 & Encosta & 14 & Presente & $\begin{array}{c}\text { Capoeira, } \\
\text { campo, lavoura }\end{array}$ & $1 / 14$ & $1 / 14$ & $10 / 14$ & $10 / 14$ \\
\hline $\mathrm{C} 1$ & Encosta & 1 & $\begin{array}{c}\text { Fonte } \\
\text { drenada } \\
\text { individual }\end{array}$ & Campo & $0 / 1$ & $0 / 1$ & $0 / 1$ & $0 / 1$ \\
\hline $\mathrm{C} 2$ & Encosta & 1 & $\begin{array}{l}\text { Fonte } \\
\text { drenada } \\
\text { coletiva }\end{array}$ & Mata & $0 / 1$ & $0 / 1$ & $0 / 1$ & $0 / 1$ \\
\hline
\end{tabular}

As fontes do grupo C são de drenagem e apresentam uma proteção mais elaborada que as anteriores; a fonte $\mathrm{C} 1$ abastece uma família e foi construída pelo próprio agricultor sem nenhum apoio técnico, e a $\mathrm{C} 2$ é de uso coletivo de dez propriedades e foi construída com apoio técnico oficial da EMATER/ASCAR/RS (Tabela 1, Figura 1).

Essas fontes apresentam proteção física na parte externa, feitas a partir de blocos de rochas de arenito ou basalto. A proteção ajuda a captar o fluxo de água da vertente para dentro de reservatórios contendo sucessivas camadas de areia (diâmetro entre $2-0,062 \mathrm{~mm}$ ) e agregados de pedras britadas de pequeno diâmetro (dimensões entre 4,8 a $9,5 \mathrm{~mm}$ ), cuja função é de filtração de particulados de tamanho silte $(0,062$ a $0,002 \mathrm{~mm})$, argila $(<0,002 \mathrm{~mm})$ e de material orgânico.

Os resultados médios das épocas de coleta foram confrontados com os padrões de qualidade de água para consumo humano, estabelecidos pela portaria 518/2004 e a resolução 357/2005 (BRASIL, 2004). Utilizou-se o teste $\mathrm{t}$, a 5\%, para comparar: i) as médias das épocas de coleta $(\mathrm{n}=8)$ entre proteções ( 1 x 2), ou seja, A1vsA2, B1vsB2 e C1vsC2; ii) as médias das épocas de coleta em cada grupo $(n=16)$, ou seja, AvsB; AvsC e BvsC. Os valores de coliformes totais foram transformados pela expressão $\log \mathrm{Y}+1$ por não apresentarem valores com distribuição normal.

Na discussão, adotar-se-á a seguinte nomenclatura: fontes A (paisagem de Baixada), onde A1 são as fontes sem proteção e A2 com proteção; fontes B (paisagem de Encosta), onde B1 são sem proteção e $\mathrm{B} 2$ com proteção; fontes $\mathrm{C}$ (fontes drenadas), onde $\mathrm{C} 1$ é uma fonte drenada rudimentar 
para abastecimento de uma residência e C2 fonte drenada elaborada nas normas técnicas para abastecimento coletivo de 10 residências.

\section{RESULTADOS E DISCUSSÃO}

Todas as águas amostradas apresentarem valores de conteúdo de sais dissolvidos inferiores a $500 \mathrm{mg} \mathrm{L}^{-1}$ e a condutividade elétrica variou de 4 a $347 \mu \mathrm{S} \mathrm{cm}^{-1}$, o que as caracterizam como água doce de acordo com a Resolução n 357/2005.

TABELA 2. Parâmetros físicos e microbiológicos em águas de 36 fontes utilizadas pelos agricultores da pequena bacia hidrográfica do Arroio Lino, Agudo - RS, no ano de 2002. Physical and microbiological parameters of groundwater from 36 sources used for human consumption in the Arroio Lino watershed, Agudo, RS, in 2002.

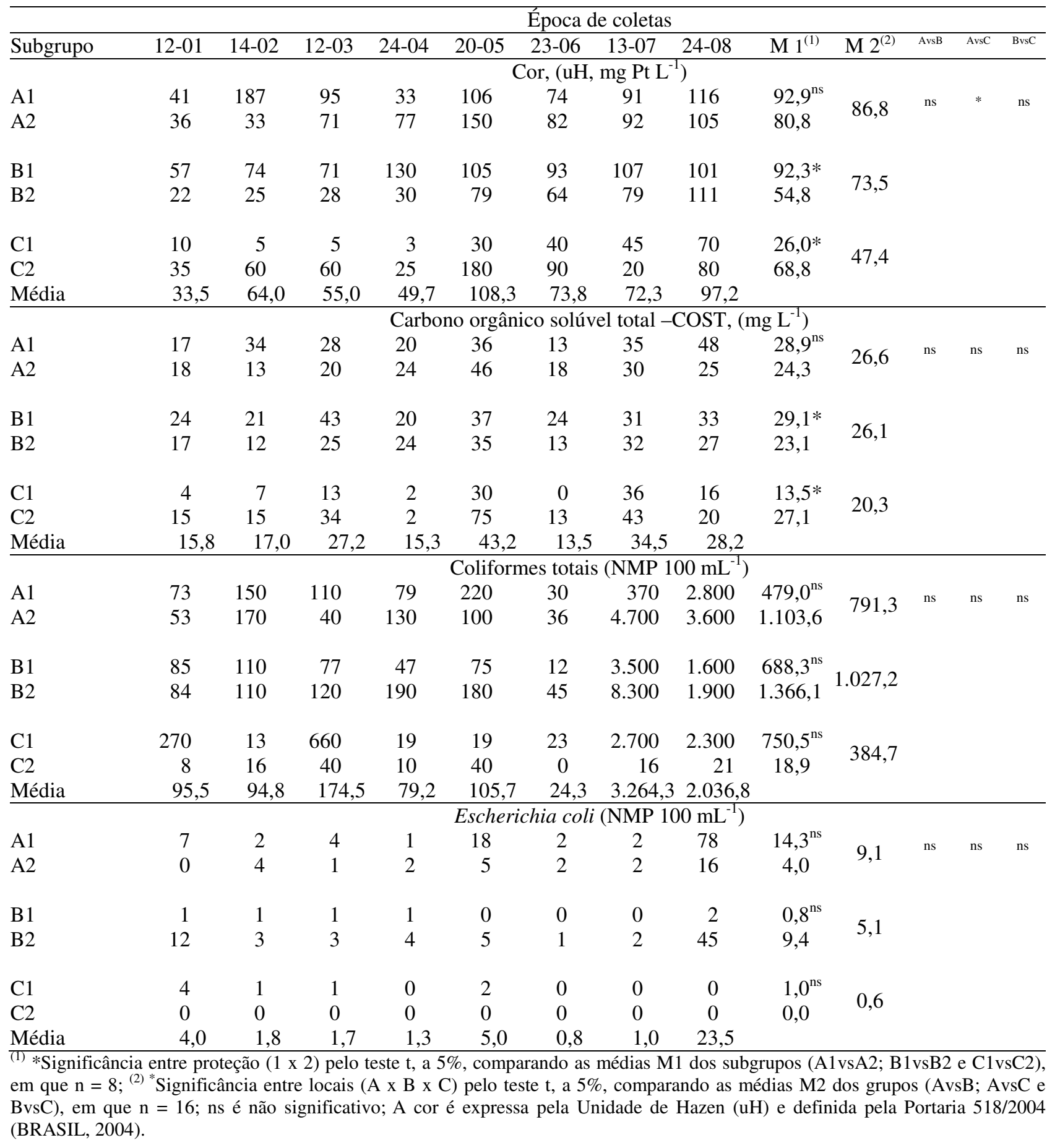


Na Tabela 2, a cor variou de 33,5 a 108,3 uH entre as épocas de amostragem. Nenhuma época de avaliação apresentou água com valores inferiores ao valor máximo permitido (VMP) para cor, fixado em $15 \mathrm{uH}$ pela Portaria 518/2004 (BRASIL, 2004), para águas de consumo humano. Contudo, em geral, os valores observados nos meses de verão, entre janeiro e abril, tenderam a ser menores que aqueles observados nos meses de inverno (maio a agosto), estando associados a menor pluviosidade no verão, logo menor probabilidade de presença de sólidos suspensos. Em média, a cor apresentou valor de $87 \mathrm{uH}$ para a água do grupo A (Baixadas), $74 \mathrm{uH}$ para o grupo B (Encosta) e $47 \mathrm{uH}$ para o grupo C. As fontes drenadas, com proteção mais elaborada, representadas pelo subgrupo $\mathrm{C} 1$, apresentaram, na média, valor inferior às demais, o que indica maior proteção com relação às demais para esse parâmetro (Tabela 1). $\mathrm{O}$ uso de proteções, mesmo rústicas, mostrou-se determinante com relação a esse parâmetro nas fontes do subgrupo B (Tabela 1).

O teor de carbono orgânico solúvel total não mostrou diferenças entre os subgrupos A, B e C (Tabela 1). Já o subgrupo B de fontes com proteção (B2) apresentou menor teor de COST, como também a fonte individual (C1). Isso se deve, provavelmente, a maior produção de sedimentos nas partes altas do relevo, quando associadas a sistemas agrícolas (MERTEN \& MINELLA, 2006). A entrada de material sólido nas fontes é apontada por ANDRADE et al. (2007) como fator principal responsável pela diminuição da qualidade de águas superficiais. Assim, ao entrar sedimentos nas fontes, os valores de cor e de compostos orgânicos solúveis podem ser incrementados.

$\mathrm{Na}$ Tabela 2, a presença de coliformes totais variou de zero a $8.300 \mathrm{NMP} 100 \mathrm{~mL}^{-1}$, estando presentes em todas as fontes, independentemente da época de avaliação, seguindo a tendência para as duas variáveis anteriores, que foram maiores nos meses de inverno. No entanto, a posição na paisagem das fontes $\mathrm{A}, \mathrm{B}$ e $\mathrm{C}$ não foi determinante na qualidade da água para esse parâmetro, apresentando-se com médias não diferentes estatisticamente entre si e entre as fontes protegidas e não protegidas (1 e 2).

Em geral, as concentrações de E. coli foram menores que as de coliformes totais, que variaram de zero a 47 NMP $100 \mathrm{~mL}^{-1}$. Esse parâmetro apresentou grandes discrepâncias entre as épocas de coleta, principalmente entre a última e as demais (Tabela 1). De acordo com os padrões de potabilidade da água (BRASIL, 2004), apenas a fonte C2 apresentou-se isenta de E. coli; $\log$, potável, segundo esse parâmetro. Apesar de a análise estatística não mostrar diferenças entre as médias das fontes com e sem proteção, do ponto de vista qualitativo, percebe-se menor probabilidade de contaminação microbiológica nas fontes protegidas drenadas, principalmente a coletiva, C2.

Na Tabela 3, o pH das amostras de água variou de 4,8 e 7,0, indicando um caráter de ácido a neutro. As épocas de coleta apresentaram valores de $\mathrm{pH}$ que tendem a ser menores para o verão (meses de janeiro a abril) que para os meses de maio e junho. Isto pode estar associado ao maior tempo de contato sedimento-água, favorecendo a liberação de prótons na água por parte de partículas sólidas. Entre os subgrupos relativos à proteção $(1$ e 2), apenas as fontes drenadas $(\mathrm{C} 1 \mathrm{e}$ C2) diferiram entre si. A fonte $\mathrm{C} 2$ apresentou $\mathrm{pH} 5,3$, e foi em média inferior a $\mathrm{C} 1(\mathrm{pH} 6,6)$, e a média desses não diferiu em relação aos outros subgrupos A e B com pH de 6,1 e 6,3. Esses valores podem ser considerados de pouca amplitude, mas são inferiores aos encontrados por BUENO et al. (2005) para águas superficiais. Esse parâmetro é importante para a microbiologia, respondendo de forma inversa a parâmetros como coliformes totais (ANDRADE et al., 2007).

O fósforo total - PT, variou em média de 0,01 a $0,71 \mathrm{mg} \mathrm{L}^{-1}$, sem diferir entre as épocas de coleta (Tabela 3). A posição na paisagem mostrou-se efetiva apenas para os subgrupos A e C, onde se observaram, respectivamente, os valores de $0,14 \mathrm{mg} \mathrm{L}^{-1}$ e $0,24 \mathrm{mg} \mathrm{L}^{-1}$. As fontes do subgrupo posicionado nas baixadas não diferiram dos subgrupos A2 e B2 (Tabela 3). A fonte C1 apresentou, na média, o maior teor de fósforo total $\left(0,39 \mathrm{mg} \mathrm{L}^{-1}\right)$, comparado a $\mathrm{C} 2$ e ao grupo A (Tabela 3). O P, por estar associado à fração sólida, as fontes não protegidas têm maior probabilidade de receberem material externo e apresentarem valores altos de $\mathrm{P}$ na água. Contudo, as fontes que compõem o subgrupo $\mathrm{C}$ apresentou PT elevado, o que sugere que grande parte do $\mathrm{P}$ presente nessas amostras se 
encontre em estado solúvel, como observaram PELLEGRINI et al. (2010). Uma vez que a Portaria n518/2004 não fixou padrões de potabilidade em relação a este elemento, buscou-se complementação na Resolução n³57/2006 do CONAMA (BRASIL, 1986), considerando-se as águas das fontes alternativas de abastecimento da zona rural como sendo de ambiente lótico.

TABELA 3. Parâmetros químicos na água de 36 fontes utilizadas pelos agricultores da pequena bacia hidrográfica do Arroio Lino, Agudo - RS, ano de 2002. Chemical parameters of groundwater from 36 sources used for human consumption in the watershed of Arroio Lino, Agudo, RS, in 2002.

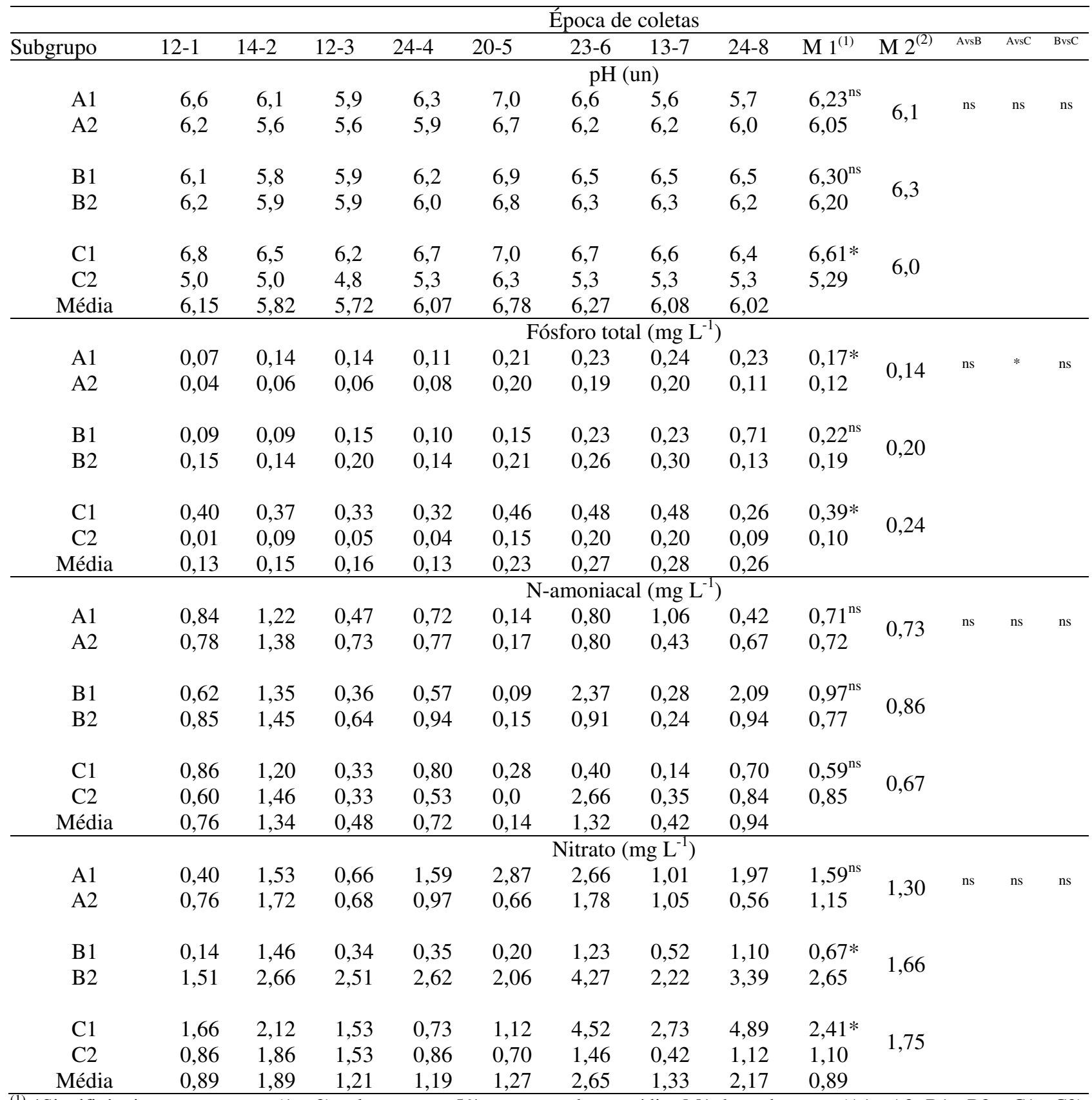

(1) *Significância entre proteção (1 x 2) pelo teste t, a 5\%, comparando as médias M1 dos subgrupos (A1vsA2; B1vsB2 e C1vsC2), em que $\mathrm{n}=8$; ${ }^{(2)}$ *Significância entre locais (A x B x C) pelo teste t, a 5\%, comparando as médias M2 dos grupos (AvsB; AvsC e BvsC), em que $n=16$; ns é não significativo; A cor é expressa pela Unidade de Hazen (uH) e definida pela Portaria 518/2004 (BRASIL, 2004).

A concentração de nitrogênio nas águas na forma de $\mathrm{N}$-amoniacal $\left(\mathrm{N}-\mathrm{NH}_{3}\right)$ variou de zero a $2,66 \mathrm{mg} \mathrm{L}^{-1}$. Os valores médios de $\mathrm{N}^{-\mathrm{NH}_{3}}$ encontram-se ora superiores, ora inferiores ao VMP determinado pela portaria 518/2004 como sendo $1,5 \mathrm{mg} \mathrm{L}^{-1}$. Valores acima do VMP ocorreram no subgrupo (B1) sem proteção, em $25 \%$ das amostras no período de outono-inverno e no subgrupo 
(C2) drenada, em $13 \%$ das amostras de outono. Para o $\mathrm{N}-\mathrm{NH}_{3}$, não foram observadas diferenças entre os subgrupos A, B e C nem entre as fontes protegidas e não protegidas. Entre as épocas de coleta somente as médias dos meses de fevereiro e junho mostraram-se discrepantes. Isso denota que pode ter havido uma contaminação pontual no tempo, sem relação com o período de chuvas.

A concentração de nitrogênio nas água,s na forma de $\mathrm{N}$-nitrato $\left(\mathrm{N}-\mathrm{NO}_{3}\right)$, variou de 0,14 a $4,89 \mathrm{mg} \mathrm{L}^{-1}$. No entanto, esses valores encontram-se abaixo de $10 \mathrm{mg} \mathrm{L}^{-1}$ determinado pela portaria 518/2004 como sendo o valor máximo permitido (BRASIL, 2004). A localização das fontes na paisagem não se mostrou determinante para esse parâmetro. As fontes do subgrupo B mostraram-se diferentes quanto à contaminação de Nitrato, ou seja, as fontes não protegidas apresentaram, em média, maior teor de $\mathrm{N}_{-} \mathrm{NO}_{3}$. Já o maior teor na fonte $\mathrm{C} 1$, em comparação à $\mathrm{C} 2$, pode estar associada à vazão diferenciada entre uma e outra fonte.

A presença de $\mathrm{N}-\mathrm{NO}_{3}$ está relacionada às práticas de fertilização nítrica na cultura do fumo e, segundo KAISER (2006), as altas concentrações de $\mathrm{N}_{-} \mathrm{NO}_{3}\left(>120 \mathrm{mg} \mathrm{L}^{-1}\right)$ medidas na água superficial podem ser atribuídas à adubação nitrogenada na cultura do fumo.

Em resumo, as fontes drenadas que compõem os subgrupos $\mathrm{C} 1$ e $\mathrm{C} 2$ apresentaram menor valor para a cor e maior para PT. Apesar de não apresentarem diferenças estatísticas, as fontes $\mathrm{C} 1 \mathrm{e}$ C2 apresentaram-se com valores, na média, inferiores às demais para E. coli, coliformes totais, COST, pH, cor e $\mathrm{N}-\mathrm{NH}_{3}$ o que demonstra qualitativamente uma efetividade em evitar contaminação. Vale ressaltar que apenas a fonte $\mathrm{C} 2$ apresenta valores de $E$. coli em acordo com os padrões de potabilidade (BRASIL, 2004).

Da mesma forma, as fontes do subgrupo A apresentaram para PT valores menores que para o subgrupo C. O tempo de permanência da água no interior das fontes drenadas, principalmente a $\mathrm{C} 1$, que é individual, é maior. Isso pode ter aumentado a probabilidade de contaminação cumulativa da água, com reflexos em alguns parâmetros.

Pode-se inferir quanto à época de coleta que todos os parâmetros, com exceção da E. coli, tenderam a variar seus teores entre os meses de coleta. É provável que isso possa estar associado ao regime hídrico e às práticas agrícolas de fertilização. Por exemplo, os teores de coliformes totais foram maiores em períodos chuvosos (meses de inverno), enquanto o $\mathrm{P}$ total tendeu a ser menor nos meses secos, visto que o carregamento superficial de $\mathrm{P}$ particulado ou biodisponível é maior em unidades paisagísticas mais antropizadas e nos períodos de maior pluviometria (PELLEGRINI et al., 2008). No caso do aumento dos teores de $\mathrm{N}\left(\mathrm{NH}_{3}\right.$ e $\left.\mathrm{NO}_{3}\right)$, as práticas culturais na área da pequena bacia hidrográfica parecem determinar a variação temporal, concordando com observações de KAISER (2006).

Para as 12 fontes locadas na baixada (A), houve tendência de as mesmas apresentarem, em média, valor menor de fósforo total, em relação ao subgrupo $\mathrm{C}$, no entanto é importante ressaltar que a proteção rudimentar para essas fontes mostrou-se eficiente para o PT. Para as fontes do grupo $\mathrm{B}$, pode-se dizer o mesmo, para a cor, COST e Nitrato. Esta interpretação discorda em parte das observações realizadas por AMARAL et al. (2003), que verificaram uma preservação da qualidade da água em fontes locadas nas cotas mais altas do relevo. A razão disso é que, nas 14 fontes desse estudo, mesmo estando na posição de encosta com proteção, elas se encontravam em posição de drenagem e de recebimento de material externo. A entrada de contaminantes via subsuperficial é apontada por ANDRADE et al. (2007) como o fator responsável por 1/3 da contaminação de águas superficiais.

Nesse sentido, pôde-se inferir que a proteção física construída de forma rudimentar pelos agricultores ao redor das fontes (A2 e B2) não garantiu a qualidade da água. A ineficiência dessas estruturas quanto ao isolamento é notória frente à entrada de água superficial e de contaminantes. A proteção mais eficaz foi do tipo fonte drenada construída nas normas técnicas $(\mathrm{C} 2)$, principalmente quando utilizamos o atributo microbiológico, cujos parâmetros E. coli e coliformes totais mostraram maior qualidade das águas avaliadas (Tabela 2). A ausência de benfeitorias construídas nas 
proximidades das fontes $\mathrm{C} 1$ e C2 (Tabela 1) pode também ter contribuído para a menor pressão de poluição e contaminação dessas águas e também pode a demanda coletiva de água da fonte $\mathrm{C} 2$ ter minimizado os níveis de contaminação decorrente do efeito de diluição.

Portanto, mesmo que o uso de dispositivos de proteção das fontes seja eficaz, trata-se de uma ação paliativa aos efeitos negativos da ação antrópica no ambiente. Os resultados desse trabalho convergem com aqueles obtidos por BALDISSERA (2002), onde apenas 14,5\% de 1.340 amostras de água superficial no meio rural, em Santa Catarina, foram consideradas próprias para o consumo humano. Assim, o planejamento em escala de pequenas e microbacias hidrográficas de cabeceiras é fundamental, a fim de diminuir a pressão de poluição em áreas de nascentes. Entretanto, ações que mitigam a contaminação do solo e das águas, como a presença de cinturão verde com espécies florestais nativas no entorno de mananciais (DONADIO et al., 2005; BORTOLUZZI et al., 2006), o adequado tratamento de dejetos (SANTOS et al., 2007), a diminuição da área de cultivo e da pressão de poluição da ação antrópica (PELLEGRINI et al., 2008) são necessárias, principalmente em pequenas bacias hidrográficas de cabeceiras.

\section{CONCLUSÕES}

As águas das fontes de captação apresentam variações temporais em seus parâmetros físicoquímicos e microbiológicos, devido ao clima e às práticas agrícolas, ora permanecendo acima dos padrões de potabilidade, ora abaixo.

A fonte drenada coletiva, sistema recomendado pela assistência técnica oficial, mostrou-se a mais eficaz em evitar a contaminação por Escherichia coli, restringindo também coliformes totais, fósforo total e $\mathrm{N}-\mathrm{NO}_{3}$ em relação à fonte individual. A posição das fontes na paisagem e a presença de proteção física rudimentar podem ser utilizadas como critério parcial ao uso de fontes para captação de água.

\section{REFERÊNCIAS}

AMARAL, L.A.; NADER FILHO, A.; ROSSI JUNIOR, O.D. Água de consumo humano como fator de risco à saúde em propriedades rurais. Revista Saúde Pública, São Paulo, v.37, n.4, p.510514, 2003.

ANDRADE, E.M.; ARAÚJO, L.de F.P.; ROSA, M.F.; DISNEY, W.; ALVES, A.B. Seleção dos indicadores da qualidade das águas superficiais pelo emprego da análise multivariada. Engenharia Agrícola, Jaboticabal, v.27, n.3, p. 683-690, 2007.

APHA. AMERICAN PUBLIC HEALTH ASSOCIATION. Standard methods for the examination of water and wastewater. $16^{\text {th. }} \mathrm{ed}$. New York, 1992.

BALDISSERA, T.I. Poluição por dejetos de suínos no oeste catarinense. Agropecuária Catarinense, Florianópolis, v.15, n.1, p.11-2, 2002.

BORTOLUZZI, E.C.; RHEINHEIMER, D.S.; GONÇALVES, C.S.; PELLEGRINI, J.B.R.; ZANELLA, R.; COPETTI, A.C.C. Contaminação de águas superficiais por agrotóxicos em função do uso do solo numa microbacia hidrográfica de Agudo - RS. Revista Brasileira de Engenharia Agrícola e Ambiental, Campina Grande, v.10, n.4, p.881-887, 2006.

BORTOLUZZI, E.C.; RHEINHEIMER, D.S.; GONÇALVES, C.S.; PELLEGRINI, J.B.R.; MARONEZE, A.M.; KURZ, M.H.S.; BACAR, N.M.; ZANELLA, R. Investigation of the occurrence of pesticide residues in rural wells and surface water following application to tobacco. Química Nova, São Paulo, v.30, n.8, p.1.872-1.876, 2007.

BRASIL. Ministério da Saúde. Portaria n⿳0 518/ de 25 de março de 2004. Brasília, 2004. 17 p.

BRASIL. Ministério do Desenvolvimento Humano e Meio Ambiente. Resolução: CONAMA no 20 de 10 de junho de 1986. Brasília, 1986. 92 p. 
BUENO, L.F.; GALBIATTI, J.A.; BORGE, M.J. Monitoramento de variáveis de qualidade da água do horto Ouro Verde - Conchal - SP. Engenharia Agrícola, Jaboticabal, v.25, n.3, p.742-748, 2005.

DONADIO, N.M.M.; GALBIATTI, J.A.; PAULA, R.C. de. Qualidade da água de nascentes com diferentes usos do solo na bacia hidrográfica do Córrego Rico. São Paulo, Brasil. Engenharia Agrícola, Jaboticabal, v.25, n.1, p.115-125, 2005.

FERNANDES NETO, M.L.; SARCINELLI, P.N. Agrotóxicos em água para consumo humano: Uma abordagem de avaliação de risco e contribuição ao processo de atualização da legislação brasileira. Engenharia Sanitária e Ambiental, Rio de Janeiro, v.14, n.1, p.69-78, jan. 2009.

GRÜTZMACHER, D.D.; GRÜTZMACHER, A.D.; AGOSTINETTO, D.; LOECK, A.E.; ROMAN, R.; PEIXOTO, S.C.; ZANELLA, R. Monitoramento de agrotóxicos em dois mananciais hídricos no Sul do Brasil. Revista Brasileira de Engenharia Agrícola e Ambiental, Campina Grande, v. 2, n. , p.632-637, 2008.

KAISER, D.R. Nitrato na solução do solo e na água de fontes para consumo humano numa microbacia hidrográfica produtora de fumo. 2006. 114 f. Dissertação (Mestrado em Ciência do Solo) - Universidade Federal de Santa Maria, Santa Maria, 2006.

MERTEN, G.H.; MINELLA, J.P. Impact on sediment yield due to the intensification of tobacco production in a catchment in Southern Brazil. Ciência Rural, Santa Maria, v.36, n.2, p.669-672, 2006.

MINELLA, J.P.; MERTEN, G.H.; REICHERT, J.M.; RHEINHEIMER D.S. Identificação e implicações para a conservação do solo das fontes de sedimentos em bacias hidrográficas. Revista Brasileira de Ciência do Solo, Viçosa-MG, v.31, n.6, p.1.637-1646, 2007.

PIZZELLA, D.G.; SOUZA, M.P. de. Análise da sustentabilidade Ambiental do Sistema de Classificação das águas doces superficiais brasileiras. Engenharia Sanitária e Ambiental, Rio de Janeiro, v.12, n.2, p.139-148, 2007.

PELLEGRINI, J.B.R.; RHEINHEIMER, D.S.; GONÇALVES, C.S.; COPETTI, A.C.C.; BORTOLUZZI, E.C. Adsorção de fósforo em sedimentos e sua relação com a ação antrópica. Revista Brasileira de Ciência do Solo, Viçosa-MG, v.32, n.7, p.2.639-2.646, 2008.

PELLEGRINI, J.B.R.; RHEINHEIMER, D.S.; GONÇALVES, C.S.; COPETTI, A.C.C.; BORTOLUZZI, E.C.; TESSIER, D. Impacts of anthropic pressures on soil phosphorus availability, concentration, and phosphorus forms in sediments in a Southern Brazilian watershed. Journal of Soils and Sediments, Hamburg, v.10, p.451-460, 2010.

RHEINHEIMER, D.S.; GONÇALVES, C.S.; PELLEGRINI, J.B.R. Impacto das atividades agropecuárias na qualidade da água. Ciência \& Ambiente, Santa Maria, v.27, n.2, p.85-96, 2003.

SANTOS, M.A.A.dos; SCHMIDT, V.; BITENCOURT, V.C.; MAROSO, M.T.D. Esterqueiras: avaliação físico-química e microbiológica do dejeto suíno armazenado. Engenharia Agrícola, Jaboticabal, v.27, n.2, p.537-543, 2007. 